\title{
THE USE OF PAST ASSESSMENTS AS A DEDUCTIVE LEARNING TOOL? PERCEPTIONS OF STUDENTS AT A SOUTH AFRICAN UNIVERSITY
}

\author{
J. M. Ontong* \\ e-mail: ontongi@sun.ac.za / https://orcid.org/0000-0001-5097-8988
}

\author{
A. Bruwer* \\ e-mail: bruwera@sun.ac.za \\ *School of Accountancy \\ Stellenbosch University \\ Stellenbosch, South Africa
}

\section{ABSTRACT}

Promoting critical thinking skills in the higher education setting is noted as a key skill required by students. Using a questionnaire approach, this study examined whether first-year students perceived the use of past assessments in preparation for upcoming assessments as a deductive learning tool and used them solely as a study aid and predictor at a South African university, with the focus on the deductive and conductive learnings styles, with specific reference to whether students perceive the past assessments to be used as tools to indicate specifically what will be assessed in terms of historical frequency. The findings suggest that students utilise past assessments as a deductive tool in order to predict future areas that will be assessed, as well as certain characteristics, such as the level of difficulty of question papers. The authors argue that when past assessments are used as a deductive "predictor" of future assessment, this then potentially acts as an inhibitor of developing critical thinking skills. The findings therefore, although acknowledging the value added in terms of higher education students of the revision and practising of past assessments, highlight that assessors in higher education need to be conscious that the use of past assessments as a "predictor" through the repetitive nature of the items being assessed may result in students who are able to pass assessments but who are unable to necessarily demonstrate critical thinking skills as required by module outcomes. The findings of this study therefore present various streams of areas for future research into the better understanding of how past assessments can be used in order to promote critical thinking within higher education modules.

Keywords: deductive learning, critical thinking, prior-year assessments, study aid, past papers

\section{INTRODUCTION}

Analysing the past to prepare for the future has been a long-standing thought within the literature (Webster and Watson 2002). This school of thought encourages students at a high 
school level to practise previous academic years' assessments, noting these as a key study aid in an attempt to achieve academic success (Careers24.com 2019). The success of the use of these study aids leads to students attempting to replicate learning styles that they have found effective in the past, in future academic environments such as a higher education environment. Dwyer, Hogan and Stewart $(2014,43)$ define critical thinking as "a metacognitive process that, through purposeful, reflective judgement, increases the chances of producing a logical conclusion to an argument or solution to a problem". Dwyer et al. (2014) further argue that providing instruction to students that emphasises the use of critical thinking is becoming invaluable in students' better understanding of complex information. It is therefore suggested that students who are able to critically analyse content are able to answer questions based on their understanding of the content and not merely based on a memorisation of prior assessments questions, memorandums and styles for examination purposes. By obtaining the perceptions of first-year students, this study attempted to understand and analyse student perceptions of the use of previous academic years' assessments as part of their learning style and approach. It further highlights the perceptions of students of their learning approaches and the development of their critical thinking skills in a higher education environment. This was done to determine whether past assessments used in a repetitive manner in the compilation of new assessments and used during lectures lead to a comfort space created for the students of expected questions and answers, as opposed to challenging critical thinking.

The literature suggests that review and practising of previous academic years' assessments have various perceived benefits, such as highlighting areas frequently assessed, providing additional practising of questions and revision of key concepts, as well as giving students a perceived comfort level of the standard to be expected in future assessments, as the expectation of the examination type could determine the learning approach applied by a student (Smith and Miller 2005). Students adapt specific styles of preparation for assessment based on the expectation of the assessment style (Broekkamp and Van Hout-Wolters 2007). It could be argued that previous academic years' assessments are important for learners when developing an expectation of the assessment style of a topic, as well as the assessment terminology and vocabulary used. It is with that notion that this study aimed to add to the existing literature by identifying the gap in the understanding of the usage of past assessments in a higher education setting and further suggesting better application of past assessments in order to develop criticalthinking students, as opposed to answering expected questions with inductively studied answers. This study, in an attempt to address this gap, proposed that two research questions needed to be addressed. Firstly, what are the perceptions of students at the end of their first year regarding the use and importance of previous academic years' assessments in their tertiary 
studies? Secondly, what do students at the end of their first year perceive to be the benefits, hindrances, and uses of previous academic years' assessments in a higher education setting?

By using both quantitative and qualitative data as obtained via questionnaires, this study aimed to answer the research questions and further determine the theory that the higher education system is creating students who merely act as regurgitaters of academic content through familiarity with the content and patterns of previous academic years' assessments rather than producing critical thinkers through test-enhanced learning and applying an appropriate learning style. The need for critical thinkers in tertiary education is often highlighted as requiring students to critically evaluate new information presented in assessments (Dwyer, Hogan and Stewart 2012). The study further aimed to contribute to the existing literature by making suggestions to lecturers involved in higher education, as well as teachers at school level, regarding the development of their own pedagogical approaches with specific reference to the use of previous years' academic assessments, as this will lead to a match of learning styles between students and lecturers.

The focus group for this study comprised students enrolled in the 2019 Financial Accounting 188 module at Stellenbosch University. This population of students was used as a proxy for all the first-year undergraduate students in the Economic and Management Sciences (EMS) Faculty. At Stellenbosch University, similar to other university offerings, students are presented with various modules, both semester and year modules. The EMS Faculty follows a flexible assessment regulation, which includes written assessments for the majority of first modules. Although this study only included the perceptions of and effect on accounting students at one university, their view, based on their needs in their specific field of study, could be different from senior students or students in other fields of study. Further limitations to this study included the emotional variable that access to past assessments might bring to a student. The comfort of knowing what to expect might decrease the students' stress and influence their final performance. It is noted that Financial Accounting 188 students form a large percentage of first-year students at the EMS Faculty, and therefore represent a suitable proxy.

The following section of this article provides a review of the existing literature that supports this study. Thereafter, the research methodology followed is presented, followed by a discussion of the findings, and finally the conclusion of the study.

The purpose of this study is to evaluate whether students are excessively dependent on past papers for their academic success, and if so, whether this trend comes from habits developed during their high school studies. The study also aimed to determine what students perceive to be the most effective learning techniques, as well as their perceptions of their academic success if they did not review past papers. 


\section{LITERATURE REVIEW}

The learning style of a student and its influences vary from lecture-taught learning, peer learning, own-experience learning, to self-assessment learning (Cilliers et al. 2010). Students apply either a deductive or inductive learning strategy, depending on the scenario presented (Decoo 1996). The strategy applied by students during their learning depends on the specific scenario presented; however, a pattern is developed within this strategy that is referred to as the student's learning style (Biggs 1978). In the development of their study style and approach, students apply available interventions, such as tutorials, class vodcasts, and revision vodcasts in order to achieve success (Bokwana and Tewari 2014). In addition to these moduleincorporated interventions, the access to and practising of past assessments could be applied as an academic intervention in the same manner. This study aimed to identify the value of past assessments as an academic intervention and their application within a first-year module. The strategy applied by students in the learning process can include either an inductive or a deductive approach (Goswami 2002). An inductive strategy is problem based and entails a process of learning through discovery and inquiry and critically analysing a problem to determine solutions (Felder 1988). The process of discovery learning through the use of past assessments as student-led learning in a flipped-classroom approach would supply students with an added intervention to apply an inductive learning strategy to learn using the available material with the lecturer as the facilitator (Fischer 1979). This process of discovery learning provides students with a platform to apply their reasoning to solve the problem posed within the assessment to develop the intellectual trait of confidence in reasoning, as suggested by the Paul-Elder critical thinking model (Paul and Elder 2010).

While the inductive strategy of learning is student focused, the deductive learning strategy is lecturer orientated. Students depend on the lecturer to identify the basic outcomes to address the knowledge needed for assessment purposes; no more and no less. This leads to an inductive strategy being the common approach in tertiary education (Felder 1988). The use of past assessments in this approach to learning has the risk of students using it as a predictor of possible assessment questions in order to regurgitate information, as opposed to a process of deeper learning and application of knowledge in assessments. This is in contrast to the growing need of students to possess problem-solving and deductive learning competencies as required by future employers (South Afican Institute of Chartered Accountants 2019). This was further highlighted in the development of the Adjusted Framework of Competencies of Chartered Accountants, with a renewed focus on the development of critical thinking. This is a need that can ideally be addressed by moving from an assessment-focused learning process to a problem- 
solving and thus inductive learning process (Nijhuis, Segers and Gijselaers 2005).

The identification of students' learning styles and strategies has led to lecturers developing their pedagogical approach to address the learning style of the students in order to induce successful learning (Dochy et al. 2007). It has been thought that students with a specific learning style achieve the best outcome if an instructional method, either deductive or inductive, which is most effective for their learning style, is applied (VanderStoep, Pintrich and Fagerlin 1996). This places the onus on the lecturers to develop their lesson plan in either an inductive or deductive manner, depending on their students and the study material. Studies have, however, indicated varying results regarding the success of teaching strategy development based on the learning styles of students (Cronbach 2002; Massa and Mayer 2006).

The current adaption of the teaching strategy of the lecturer is driven by student needs and the development of student-based teaching strategies. The task of teaching should reside with the lecturer, while the task of learning should be placed on the learner with the lecturer facilitating the learning process through developing pedagogical-approach strategies fitting to the content as opposed to the student. This study aimed to evaluate the role of the student in a test-enhanced learning process through the use of past assessments to determine whether past assessments could be applied as a teaching and learning intervention, in addition to current structures and resources.

The learning task is further influenced by the learning style adopted by the student. This style could encompass a concrete experience, reflective observation, abstract conceptualisation, as well as active experimentation (Kolb and Kolb 2013). Using past assessments in a learningstyle approach would incorporate the feeling of assessment-styled conditions in which past assessment were done, the use of past assessments in a lecturer-led example, as well as studentled review of past assessments. Previous approaches by lecturers developing specific strategies in order to address the learning styles of students have led to the development of learner-focused pedagogies (Cilliers et al. 2010). In response to the general adapted pedagogy of lecturers, it has initiated a movement of all learners to a specific learning strategy to adapt to the one chosen by the lecturer. Based on this style selected by lecturers, students tend to use past papers as predictors of assessments by using the lecturers' assessment style as scope (Ramsden 1979). The onus rests on the students as learners, as well as the lecturer who facilitates the learning process, to apply previous papers in assessment-styled conditions to create a form of selfregulated learning (VanderStoep et al. 1996). This could lead to the further development of student-led learning through a reflective learning style during the marking of completed assessments.

While the lecturer's pedagogical strategy could be developed by the lecturer to reach a 
certain objective of deeper learning, as suggested by Biggs (2001), the application of the strategy is, however, dependent on the student. In this study, the perceptions of students with regard to the use of past assessment were obtained in order to determine whether the learning strategy of the students and the teaching strategy of the lecturers are in line with creating selfregulated learning through a deductive approach, or whether past assessments are indeed used as a teaching and revision tool by lecturers, while students consider them a study hack that indicates topics and material to study in an assessment-focused process that utilises an inductive study approach. The research team aimed to address the prominence of past assessment as a dual-purpose study aid that induces expectations while regulating a process of deductive learning.

\section{RESEARCH METHODOLOGY}

A grounded theory approach was adopted as the research strategy to determine the theory of the usage of past assessments in developing the learning styles of students and critical thinkers; this was done due to the limited literature available on this topic. This approach was developed in recognition of the deductive and inductive learning approach of students, but starting from a clean slate in the application thereof. This was to enable the research team to identify trends and constructs not previously described. A questionnaire was used to obtain and analyse the participants' perceptions of previous years' assessments. The questionnaire was developed based on past literature, as discussed in the background of this study. The questionnaire was designed to capture the perceptions of the students of various aspects regarding previous academic years' assessments and the students' perceived effect of these on their academic performance and learning habits. The questionnaire included 24 Likert-scale questions ranging from: $1=$ strongly disagree to $5=$ strongly agree, with 3 as the neutral point. In addition, two ordinal-scaled questions were asked in order to quantify the perceived level of usage required when using previous years' assessments as a learning intervention. The analysis of the results of the questionnaire is discussed under the following categories:

1) Access to prior assessments;

2) Specific focus on the deductive learning style as provided through the use of past assessments;

3) Predictive value of using prior assessments in preparation for upcoming assessments; and

4) Other aspects regarding the use of past assessments. 


\section{FINDINGS}

The findings are discussed under the categories discussed above and is concluded by a discussion of other general aspects regarding past assessments.

\section{Access to prior assessments}

Table 1 shows the results of the students' perceptions regarding access to prior years' assessments and analyses the potential alternative acquisition methods in the event that access is not provided through the lecturer.

Table 1: Access to prior assessments

\begin{tabular}{|l|c|c|c|}
\hline \multicolumn{1}{|c|}{ Statement } & N & Mean & $\begin{array}{c}\text { Rounded } \\
\text { mean }\end{array}$ \\
\hline I had access to past papers for all my first-year university modules. & 218 & 3.055046 & 3 \\
\hline $\begin{array}{l}\text { If a lecturer did not make a past paper available, I would purchase this } \\
\text { from a prior-year student. }\end{array}$ & 219 & 2.383562 & 2 \\
\hline $\begin{array}{l}\text { I have not performed as strong academically in modules where past } \\
\text { papers were not available (compared to those that were available). }\end{array}$ & 220 & 3.545455 & 4 \\
\hline $\begin{array}{l}\text { In modules where lecturers do not provide past papers: The lecturer } \\
\text { does not want the class to perform well in the assessment. }\end{array}$ & 221 & 2.78733 & 3 \\
\hline $\begin{array}{l}\text { In modules where lecturers do not provide past papers: The class } \\
\text { obtains access to the past paper via alternative methods. }\end{array}$ & 221 & 3.375566 & 3 \\
\hline $\begin{array}{l}\text { I don't work through past assessments for which no suggested solution } \\
\text { is available. }\end{array}$ & 221 & 3.488688 & 3 \\
\hline $\begin{array}{l}\text { If no suggested solution is available for a past assessment, I create } \\
\text { one and ask for peer or lecturer review. }\end{array}$ & 221 & 2.276018 & 2 \\
\hline
\end{tabular}

Prior to understanding the educational value of prior assessments as a potential study tool, this study performed an analysis of the access or lack thereof that students have to prior assessments provided by lecturers. In the event that students are not given access to past assessments, possible alternative acquisition methods were suggested to the respondents. When asked whether access to past assessments (papers) was granted to students, the respondents suggested that this varied between modules (mean=3) and that not all first-year university modules made use of past assessments as a potential intervention for academic purposes. The literature provides reasons for this inconsistency. Ramsden (1979) notes that students apply past assessments as a predictor of a specific assessment style, which is counter to the teaching pedagogy of developing critical thinkers who are able to apply knowledge within different assessments and not just a specific, expected style. This suggests that certain lecturers may either view the practising of past papers as unbeneficial to students, or intentionally prefer that students do not practise or review past papers in order to, in the view of the lecturer, better prepare for upcoming assessments. The views of lecturers therefore present an area for future research.

When asked whether students would purchase past assessments from alternative sources 
if past assessments were not made available, it appears that the students disagreed with the statement (mean=2), which suggests that students would not engage in purchasing past assessments. It is, however, noted that the students strongly agreed (mean=4) with the statement that they had not performed as well academically in a module where past assessments were not available, which suggests that although there was a clear benefit associated with the use of past assessments observed by the students, a clear cost-benefit analysis was also being performed, where the costs were in certain situations deemed to exceed the benefits obtained. This statement is further supported by the respondents being neutral on the statement as to whether they would use alternative measures to obtain past assessments if they were not provided (mean=3); however, if no suggested solutions were provided, students disagreed that they would prepare their own memorandum (mean=2). This response indicates the risk of the creation of regurgitaters of information as opposed to the creation of critical thinkers, as suggested by Paul and Elder (2010). The development of their own memorandum would indicate that students applied their reasoning and critical thinking skills in the process to solve the problem.

The respondents further provided neutral responses (mean=3) to the statements that they would work through past assessments for which no suggested solutions were available, as well as the statement that lecturers who did not provide past papers had the intention of not wanting the class to perform well in upcoming assessments. This further supports the notion of a costbenefit analysis being performed, noting that the time invested into reviewing a question paper without access to the solution, for example, may outweigh the potential benefits obtained. This perhaps indicates a difference in benefits expected between the lecturer and the student. Where the lecturer expects the benefit of learning and development of critical thinking skills, the students might have an expectation of the benefit of a study hack and an indicator of assessment expectations. The negative response (mean=2), which is below the neutral point of 3 , indicates that students were not willing to create a solution with a peer or lecture review. This contributes to the theory that past assessments are used solely as predictors and study hacks as opposed to using them in a deductive learning process of critical thinking. This adds to the aspect of developing a deductive learning approach facilitated by the lecturer where the past assessment needs to be worked through by the students; however, the solution needs to be discussed as a reflective study approach.

\section{Specific focus on the deductive learning style as provided through the use of past assessments}

Table 2 shows the results of the students' perceptions of the use of past assessments as a 
potential study tool in a student's deductive learning approach to a module. The statements were further designed to identify the perceived benefits and to assist in identifying potential perceived pitfalls associated with the practising of past assessments.

Table 2: Specific focus on the deductive learning style as provided through the use of past assessments

\begin{tabular}{|l|c|c|c|}
\hline \multicolumn{1}{|c|}{ Statement } & Count & Mean & $\begin{array}{c}\text { Rounded } \\
\text { mean }\end{array}$ \\
\hline $\begin{array}{l}\text { I made use of past papers to better understand the content of my first- } \\
\text { year university modules. }\end{array}$ & 221 & 4.357466 & 4 \\
\hline $\begin{array}{l}\text { I made use of past papers in preparation for my first-year university } \\
\text { module assessments. }\end{array}$ & 219 & 4.378995 & 4 \\
\hline $\begin{array}{l}\text { I found the practising of past papers as assessment preparation to be } \\
\text { a beneficial study technique. }\end{array}$ & 220 & 4.577273 & 5 \\
\hline $\begin{array}{l}\text { The practising of past papers as assessment preparation was the only } \\
\text { assessment preparation I did. }\end{array}$ & 220 & 2.159091 & 2 \\
\hline $\begin{array}{l}\text { The practising of past papers as assessment preparation influenced my } \\
\text { academic performance. }\end{array}$ & 219 & 4.13242 & 4 \\
\hline $\begin{array}{l}\text { Practising past papers against time is an important way of learning how } \\
\text { to manage my time during an assessment. }\end{array}$ & 221 & 4.208145 & 4 \\
\hline $\begin{array}{l}\text { A past paper allows me to see an overall picture of how key concepts } \\
\text { are assessed. }\end{array}$ & 219 & 4.488584 & 4 \\
\hline $\begin{array}{l}\text { If I did not practise a past paper prior to an assessment, I would feel } \\
\text { unprepared for the assessment. }\end{array}$ & 219 & 3.958904 & 4 \\
\hline I completed the entire past paper in examination-like conditions. & 218 & 2.788991 & 3 \\
\hline $\begin{array}{l}\text { I marked my attempt and used this as an indication of where I need to } \\
\text { focus my study time as a reflective study method. }\end{array}$ & 220 & 4.05 & 4 \\
\hline $\begin{array}{l}\text { Going through past papers in class time should be part of ALL modules' } \\
\text { work curriculum. }\end{array}$ & 220 & 4.222727 & 4 \\
\hline
\end{tabular}

When asked about the potential benefits of using past assessments as a study technique, the respondents agreed (mean=5) that practising of past papers are a beneficial study method, and that using past papers is a potential mechanism to better understand the content of their firstyear modules (mean=4). This was supported by the majority of the respondents who stated that they made use of past papers in preparation for assessments (mean=4). Further insight is provided as to why the majority of the respondents made use of past papers. The reasons provided for this is that students strongly agreed that practising past papers influenced their academic performance. The students further noted that practising past papers allowed them to see an overall picture of how key concepts are assessed (mean=4) and taught them how to manage their time during an assessment (mean=4). The use of past assessments in the creation of an overall picture could build towards a holistic approach to learning and the development of critical thinking by taking a point of view within the broader spectrum to address the problem at hand. It is, however, noted that when asked if practising past assessments was done within examination conditions, the students provided an indifferent response (mean=3), which suggests that students lacked guidance on identifying whether past assessments should be used as a mechanism to teach them time management, rather as a predictive tool or for a potentially unknown other reason. 
It is noteworthy that although the students agreed that if they did not practise a past assessment, they might feel unprepared for an assessment (mean=4), but the respondents disagreed with the statement that practising past assessments was the only way to prepare for assessments. This suggests that practising past assessments, although seen as highly beneficial to the respondents, was noted as not being the sole method in preparation for an assessment, but instead one intervention among many that should be utilised in preparation for assessments. The respondents also agreed that they marked their attempts and used this as an indication of where they needed to focus study time as a reflective study method (mean=4).

Attempting to create a potential link between inductive and deductive learning, the respondents were asked whether going through past papers in class time should be part of all modules' work curriculum, to which the respondents agreed (mean=4). This suggests that providing lecturer assistance in the form of covering certain aspects regarding past assessments in a traditional class environment may provide additional value to students, other than simply making past assessments available via online portals and other channels.

\section{The predictive value of using prior assessments in preparation for upcoming assessments}

Table 3 presents the results of the students' perceptions of the predictive value of using past assessments as a potential predictor of what will be assessed in future assessments. The questions further analysed the students' perceived views on how assessments are compiled by assessors with specific reference to past assessments.

Table 3: Predictive value of using prior assessments

\begin{tabular}{|l|c|c|c|}
\hline \multicolumn{1}{|c|}{ Statement } & N & Mean & $\begin{array}{c}\text { Rounded } \\
\text { mean }\end{array}$ \\
\hline $\begin{array}{l}\text { I apply past papers as an indication of which topics within } \\
\text { modules are of importance. }\end{array}$ & 219 & 3.506849 & 4 \\
\hline $\begin{array}{l}\text { If an item was assessed during the year in an assessment, } \\
\text { the chances of it being assessed again in the year-end } \\
\text { assessment are low. }\end{array}$ & & & \\
\hline $\begin{array}{l}\text { Compilers of assessments often use past papers to set up } \\
\text { new assessments. }\end{array}$ & 219 & 3.497717 & 3 \\
\hline $\begin{array}{l}\text { If an item was assessed during the year, the chances of it } \\
\text { being assessed again in the year end-assessment are high. }\end{array}$ & 219 & 3.191781 & 3 \\
\hline
\end{tabular}

Cilliers et al. (2010) suggest that practising and reviewing prior assessments may serve as a predictor of the items to be assessed in future assessments. This predictive value is confirmed with students agreeing (mean=4) with the statement that past papers serve as an indication of which topics are seen as important for future assessments. This further suggests that students use past assessments as a potential safety net to classify the importance of work, which in turn 
may be compensating for this message having been conveyed by the lecturer directly in class, or potentially where students did not attend class, and served as an alternative delivery model for importance categorisation. Surprisingly, when asked whether an item being assessed earlier in the year has the potential of being reassessed later in other assessments such as final examinations, the students responded both to the high and low likelihood of such an occurrence with a undecided response (mean=3). Similar results are noted on the undecided response $($ mean $=3)$ as to whether the respondents perceived that compilers used past assessments as a measure to create new assessments. This suggests that although students did use prior assessments to predict upcoming questions on an assessment basis year on year, they were less likely to use past assessments within the same year as a predictor of upcoming questions in the same year and still have a degree of scepticism towards their formed predictions.

\section{Other aspects regarding the use of past assessments}

Table 4 shows the results of other potential aspects to consider regarding the use of past assessments by students as a potential study tool. Specific reference is made to quantify the magnitude of past assessments to be perceived by students as optimal.

Table 4: Other aspects regarding the use of past assessments

\begin{tabular}{|c|c|c|c|}
\hline Statement & Count & Mean & $\begin{array}{l}\text { Rounded } \\
\text { mean }\end{array}$ \\
\hline $\begin{array}{l}\text { Past papers from other institutions will give me a better } \\
\text { understanding of the work. }\end{array}$ & 220 & 2.95 & 3 \\
\hline $\begin{array}{l}\text { How far back should past papers go to be beneficial? (In } \\
\text { years) }\end{array}$ & 218 & 3.220183 & 3 \\
\hline \multicolumn{3}{|l|}{ The optimal number of past papers to practise per module is: } & \\
\hline & $\mathbf{N}$ & Percentage & \\
\hline One & 0 & 0 & \\
\hline Two & 22 & 10 & \\
\hline Three & 62 & 28 & \\
\hline More than three & 80 & 36 & \\
\hline Varies per module & 52 & 24 & \\
\hline Prefer not to say & 5 & 2 & \\
\hline Total & 221 & 100 & \\
\hline
\end{tabular}

Finally, the study asked three questions regarding general aspects related to the use of past assessments to gain a better understanding of potential administration items regarding the use of prior assessments. First, when asked whether past papers from other institutions would give students a better understanding of the work, the respondents answered with mixed responses (mean=3), which suggests that although certain students perceived there to be a benefit of using 
assessments from other institutions as an additional aid in their assessment preparation, many students, on the other hand, felt that past papers from their own institution were sufficient. When asked how far back students needed to go in terms of the number of years of past assessments to practise, the response ranged from a minimum of two years to a maximum of five years, with an average number of three years. This further suggests that all the respondents believed that past papers, when used, are beneficial as the minimum requirement was noted as two years. This, while it might be driven by time limits experienced during assessment preparation, further provides for possible changes in curricula or standards and legislation within module content. This highlights an important factor that needs to be considered by the facilitator as the use of past assessments could lead to incorrect content being used in students' preparation. When further analysing the number of past papers per module, the majority of the students responded that two or more assessments per module were deemed beneficial. It is noteworthy that a large percentage, nearly a quarter of the respondents, noted that the number of past papers to practise per module varied per module, which suggests that a one-size-fits-all approach might not be sufficient. This presents an interesting area to further research how the specific module requirements per module might differ across modules and faculties.

\section{CONCLUSION}

The use of prior assessments as a predictor of expectations has been shown to influence the expectations of students and creating a sense of comfort and familiarity that removes the pressure to think critically and analyse scenarios. This builds on identifying familiar concepts within an unfamiliar scenario and leads students to apply their concepts learned in an inductive manner through the identifying of thought triggers learned during class sessions. The comfort and control a student feels when approaching a scenario due to familiarity and the availability of multiple prior assessments indicate that past assessments could serve as a comfort space for students in their learning approach and perhaps limit the development of new learning to take place. This impacts on lecturers, who develop a standardised and generic set assessment that leads to a test of what was taught in an inductive manner and takes away from the ultimate goal of assessing in a manner that promotes critical thinking.

From the perspective of students, the use of past papers is mainly applied as a study intervention added to their current resources used and does not have a fundamental influence on their learning style and strategy. The findings suggest that access to prior assessments varies between modules, which suggests that the benefits of the use of past assessments are not understood by all lecturers. A suggested area for future research includes obtaining the various perceptions from lecturers regarding the use of past assessments. 
The findings further suggest that students regard the reviewing and practising of past assessments to have an influence on their final performance, but not on their study approach. It leaves lecturers with the role as facilitator to enable students to aptly apply prior assessments in their learning approach. Past assessments have shown a clear benefit in the deductive learning approach of students where students perceive the use thereof as a benefit in understanding difficult concepts, which leads to a partial benefit of the resource where a better understanding is obtained from past assessments through the study of solutions as opposed to the application of critical thinking and reasoning and creating their own solutions.

Additional areas of future research could include the analysis and comparison of modules that include past assessments in their study materials and class structure as opposed to modules not utilising this resource. This could set higher education standards across modules to allow students access to a study intervention that affects their final performance.

\section{REFERENCES}

Biggs, J. B. 1978. Individual and group differences in study processes. British Journal of Educational Psychology 48: 266-279.

Biggs, J. B. 2001. Enhancing learning: A matter of style or approach. In Perspectives on thinking, learning and cognitive styles, ed. R. J. Sternberg and L. Zhang, 73-102. Mahwah: Erlbaum.

Bokwana, K. G. and D. D. Tewari. 2014. Determinants of student success at a South African university: An econometric analysis. Anthropologist 17(1): 259-277.

Broekkamp, H. and B. H. A. M. van Hout-Wolters. 2007. Students' adaptation of study strategies when preparing for classroom tests. Educational Psychology Review 19: 401-428.

Careers24.com. 2019. Matrics: A past paper a week keeps your finals results on fleek. https://careeradvice.careers24.com/career-advice/career-growth/matrics-a-past-paper-a-weekkeeps-your-finals-results-on-fleek-20190724

Cilliers, F. J., L. W. T. Schuwirth, H. J. Adendorff, N. Herman and C. P. M. van der Vleuten. 2010. The mechanism of impact of summative assessment on medical students' learning. Advances in Health Sciences Education 15: 695-715.

Cronbach, L. J. (Ed.). 2002. Remaking the concept of aptitude: Extending the legacy of Richard E. Snow. Mahwah: Erlbaum.

Decoo, W. 1996. The induction-deduction opposition: Ambiguities and complexities of the didactic reality. International Review of Applied Linguistics in Language Teaching 34(2): 95-118.

Dochy, F., M. Segers, M. Segers, D. Gijbels and K. Struyven. 2007. Assessment engineering: Breaking down barriers between teaching and learning, and assessment. In Rethinking assessment in higher education: Learning for the longer term, ed. D. Boud and N. Falchikov, 87-100. Oxford: Routledge.

Dwyer, C. P., M. J. Hogan and I. Stewart. 2012. An evaluation of argument mapping as a method of enhancing critical thinking performance in e-learning environments. Metacognition and Learning 7: 219-244.

Dwyer, C. P., M. J. Hogan and I. Stewart. 2014. An integrated critical thinking framework for the $21^{\text {st }}$ century. Thinking Skills and Creativity 12: 43-52.

Felder, R. 1988. Learning and teaching styles in engineering education. Journal of Engineering Education 78: 674-681. 
Fischer, R. A. 1979. The inductive-deductive controversy revisited. The Modern Language Journal 63(3): 98-105.

Goswami, U. 2002. Inductive and deductive reasoning. In Blackwell handbook of childhood cognitive development, ed. U. Goswami, 282-302. Malden: Blackwell Publishing.

Kolb, A. Y. and D. A. Kolb. 2013. The Kolb Learning Style Inventory 4.0: A comprehensive guide to the theory, psychometrics, research on validity and educational applications. Boston: Hay Resources Direct.

Massa, L. J. and R. E. Mayer. 2006. Testing the ATI hypothesis: Should multimedia instruction accommodate verbalizer-visualizer cognitive style? Learning and Individual Differences 16(4): $321-335$.

Nijhuis, J. F. H., M. S. R. Segers and W. H. Gijselaers. 2005. Influence of redesigning a learning environment on student perceptions and learning strategies. Learning Environments Research 8: $67-93$.

Paul, R. and L. Elder. 2010. The miniature guide to critical thinking concepts and tools. Dillon Beach: Foundation for Critical Thinking Press.

Ramsden, P. 1979. Student learning and perceptions of the academic environment. Higher Education 8: 411-427.

Smith, S. N. and R. J. Miller. 2005. Learning approaches: Examination type, discipline of study, and gender. Educational Psychology 25(1): 43-53.

South Afican Institute of Chartered Accountants (SAICA). 2019. Proposed SAICA Competency Framework: CA 2025. SAICA.

VanderStoep, S. W., P. R. Pintrich and A. Fagerlin. 1996. Disciplinary differences in self-regulated learning in college students. Contemporary Educational Psychology 21: 345-362.

Webster, J. and R. T. Watson. 2002. Analyzing the past to prepare for the future: Writing a literature review. MIS Quarterly 26(2): xiii-xxiii. 